Int. J. Dev. Biol. 53: 383-391 (2009)

doi: $10.1387 / \mathrm{ijdb} .082679 \mathrm{sn}$

\title{
From Chemical Embryology to Nucleosome Patterning An interview with Roumen G. Tsanev
}

\author{
STEFAN NONCHEV ${ }^{*}, 1$ and IRINA TSANEVA ${ }^{2}$ \\ ${ }^{1}$ Institut Albert Bonniot, INSERM U823, University Joseph Fourier, Grenoble, France and ${ }^{2}$ Research Depart- \\ ment of Structural and Molecular Biology, Division of Biosciences, University College London, London, UK
}

\begin{abstract}
Roumen Tsanev was a prominent Bulgarian scientist whose pioneering ideas about the role for chromatin in cell differentiation and development led him to propose the first hypothesis for epigenetic information based on a histone code. To test experimentally his ideas, Dr.Tsanev explored nucleosome structure and heterogeneity and generated seminal data on nucleosome segregation in replicating chromatin. Roumen Tsanev made significant contributions to the understanding of chromatin changes that underlie zygotic gene activation. He identified sperm specific chromatin components tightly bound to DNA and demonstrated that the histone complement of the male pronucleus appears before the onset of DNA synthesis in the mouse zygote. In this interview, Roumen Tsanev talks about his passion for science and literature, reminisces about surmounting the harsh realities in post-war communist Bulgaria through creativity and determination, and explains what led him to propose that histones were carriers of epigenetic information. Dr. Tsanev discusses mathematical models of gene regulation and recalls computer simulations that reveal the non-linearity of genetic networks. He explains how this nonlinearity could affect cell proliferation, differentiation, development and evolution.
\end{abstract}

KEY WORDS: chromatin, histone code, epigenetics, early development, mathematical modelling, evolution

Professor Roumen Tsanev left us suddenly on July 23rd 2007 at the age of 84 . A few months earlier we talked about chromatin, developmental biology and his life in science for this Special Issue of The International Journal of Developmental Biology (IJDB). To his last days Tsanev was a man of extraordinary energy, passion and burning commitment to research; witty and provocative in a debate, a poet, scholar and philosopher, he imprinted a style of thinking on generations of young Bulgarian biologists. His whole scientific career is marked by innovation and originality - one of his early achievements was the development of RNA fractionation by gel electrophoresis. But above all, ideas - which he generated in abundance - had to be put to rigorous experimental testing. Dr Tsanev's lifelong interests lay in understanding the complex mechanisms of gene regulation that lead to cell differentiation. He was among the pioneers who tackled the structure and function of chromatin back in the sixties, as he was convinced that chromatin and particularly the histones, held the key to understanding cell differentiation. Well ahead of his time, Dr. Tsanev formulated some fundamental ideas about epigenetics based on a "histone code". He proposed a model of cell differentiation, which introduced a level of gene expression control based on long-term association of specific proteins to particular regions of DNA. In effect, Tsanev's model suggested ahead of his time the heritable influence of chromatin silencing at developmentally regulated loci. Aficionado of mathematical methods he tested his ideas about gene regulation in multicellular organisms and epigenetics using mathematical modelling and computer simulations. The model systems included epidermal proliferation, liver regeneration and tumour malignancies.

To search for experimental evidence for his epigenetic ideas Tsanev and his group embarked on a research programme starting with analysis of histone variants in the early seventies, and later, nucleosome heterogeneity and segregation during replication. In the late eighties, Tsanev developed experimental approaches to investigate zygote genome activation in the early mammalian embryo and obtained seminal data about tightly bound proteins on DNA and ultrastructures in ram sperm nuclei. Using pronuclear microsurgery and electron microscopy, Tsanev studied the dynamics of protamine to histone replacement, DNA replication and

Abbreviations used in this paper: BAS, Bulgarian Academy of Sciences.

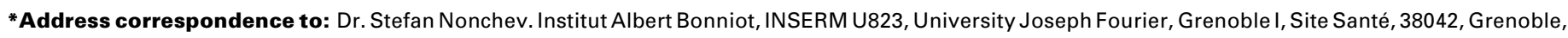
Cedex 6, France. Fax: +33-476-54-9595. e-mail: snonchev@ujf-grenoble.fr
}

Published online: 28 April 2009.

ISSN: Online 1696-3547, Print 0214-6282 
nucleosome assembly in the freshly fertilised mouse egg.

He was deeply convinced that the nucleosomes are "patterned" by histone variants and dedicated a tremendous amount of work to investigate nucleosome heterogeneity and analyse histone variants in heterochromatin of mouse and midge (Glyptotendipes barbipes), polytene chromosomes in different developmental contexts. More recently $\mathrm{Dr}$. Tsanev focused on the role of genetic networks in the process of evolution, highlighting the sophisticated concept of genomic non-linearity.

Roumen Tsanev was a man of moral integrity. He started his career under the political oppression of Lyssenko and spent the greater part of his professional life in the stifling world of "realsocialism". Through all this time he fostered and protected talented people at odds with the official ideology. The memory of these years is now fading away, but those who were there will not forget how Roumen Tsanev endorsed and stood by the values of intellectual freedom refusing to be intimidated by political pressure. He firmly believed that molecular biology held a key to improving human health and understanding die Welt im Innersten Zusammenhält ${ }^{1}$. Roumen Tsanev had a magical personality, and was able to capture and galvanize your imagination with few words and gestures. He was a fascinating speaker with the charm of a Hidalgo convinced in the rational certainty of his dreams.

As a classical warming up introduction, would you try to describe the sources of your inspiration to get involved in Developmental Biology?

\section{Between Science and Art}

Since my childhood I was fascinated by the wonderful world of living creatures. I enjoyed collecting insects and spending hours in observing the life of spiders. This was in spite of having been born in a family of litterateurs - my father was a well-known literary critic, my mother was a poetess and our home was a place continuously visited by Bulgarian writers and people of art. I deviated from this world of art and with the years became more and more interested in the secrets of Nature, wanting to understand one day what die Welt im Innersten zusammenhält? ${ }^{1}$ (Goethe, Faust ). Nevertheless, a vivid interest in literature and especially in poetry remained - for better or for worse - as an inherited burden in my life. This tragedy of Goethe affected me so deeply that its translation into Bulgarian became my hobby since my youth. My translation of "Faust" in Bulgarian was published only last year to my great satisfaction from the point of view of the translation but not from that of my understanding "what the universe engirds"!

Along with my constant involvement in scientific research I was deeply sensitive to poetry and even tried to write verses, which I dared to publish in two booklets only recently. One of my verses was dedicated to DNA whose structural beauty inspired me to write the verse "The Double Helix" which begins:

Our Mother Nature, frenziedly witted,

had the double helix so nicely knitted.

\section{The scientist}

Very early I realized that knowledge in chemistry, physics and mathematics would be needed to understand life. In 1941 I graduated from a Gymnasium in Sofia with a special prize for mathemat-

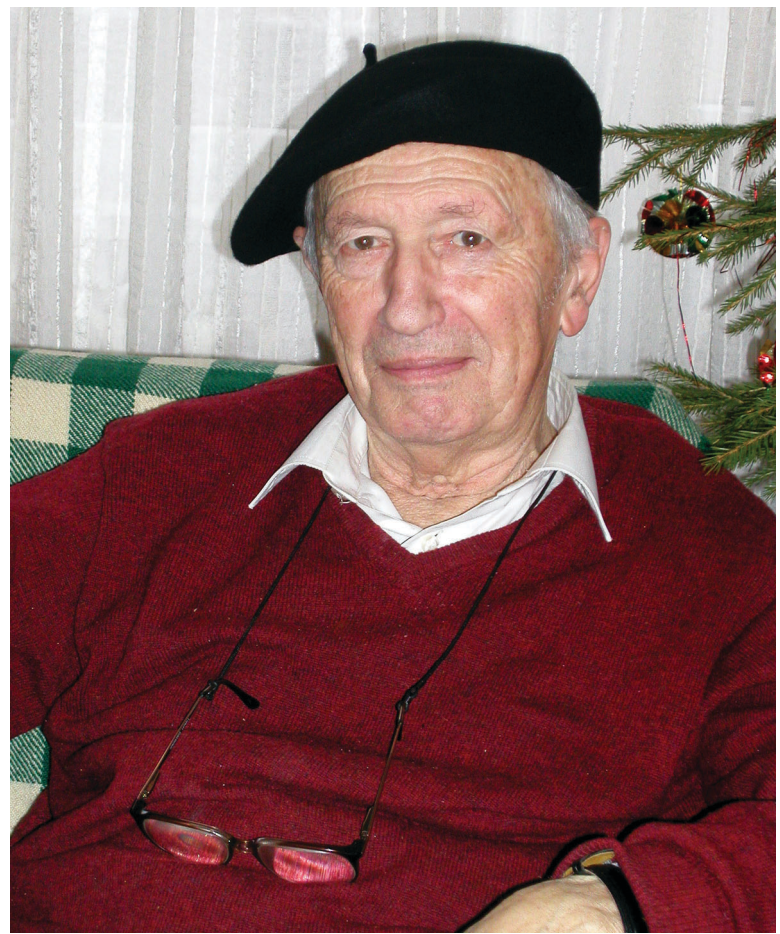

Fig. 1. Between Science and Art. "The charm of a Hidalgo convinced in the rational certainty of his dreams". After authoring more that 200 scientific papers, Dr. Tsanev finished the Bulgarian translation of Faust by Goethe in 2005.

ics. At that time the Medical Faculty in Sofia University offered the best opportunity for studying life sciences and I graduated in Medicine, but never used my medical knowledge as a GP except on my two daughters - a practice which they fortunately survived.

Soon after I obtained my degree in Medicine I met the famous Bulgarian geneticist Doncho Kostov who recruited me as his research assistant in the newly founded Institute for Applied Biology and Development of Organisms - an Institute at the Bulgarian Academy of Sciences, which opened up in 1946 with no rooms, no staff and no equipment. Long years followed in the worst working conditions and under the pressure of the officially imposed pseudoscience of Lyssenko. Such was the situation more than a half-century ago when I started my scientific carrier. Unfortunately D. Kostov, who had actively opposed Lyssenko during his work in the USSR, soon died of heart failure under the pressure to recognize the teaching of Lyssenko.

After the death of $D$. Kostov, his institute merged with the institute of Biology led by another famous Bulgarian biologist Methodi Popov. There I founded a small laboratory, which later became an independent unit at the Bulgarian Academy of Sciences (BAS) under the name of "Central Biochemical Laboratory", where in 1954 I was appointed as Director.

With a group of young enthusiasts I started research on the structure and function of nucleic acids under the worst post-war conditions. Moreover, nucleic acids were a dangerous field under the situation created by the total submission of our authorities to the pseudoscientific ideas imposed by Lyssenko. To this should be

1 "What the universe engirds" Faust by J.W. von Goethe. p.I, Penguin Books, 1949. English translation by Ph.Wayne. 


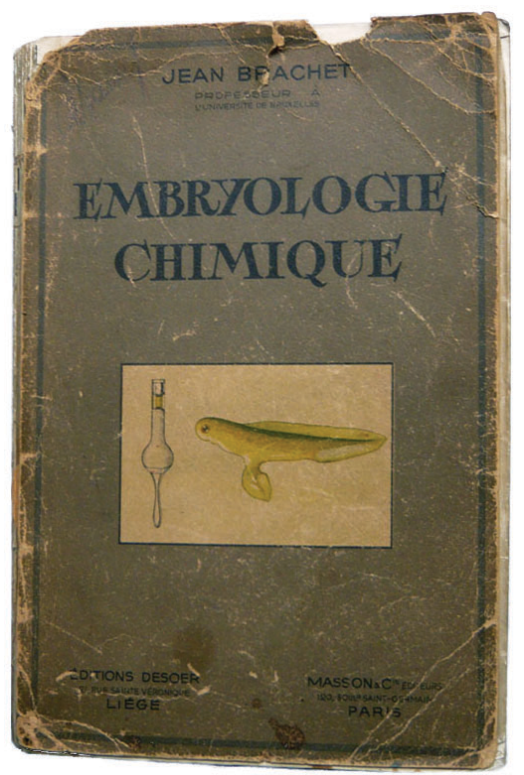

Fig. 2. "The Bible" of the newly founded "Central Laboratory of Biochemistry" (1954).

added the difficulties, sometimes the impossibility, to publish in western journals.

Very early my imagination to start studies on nucleic acids was excited by two books: the first was a volume of the English Society for Experimental Biology containing the papers read at the first Symposium on nucleic acids held in Cambridge in 1947 brought to me by D. Kostov. The second was the wonderful book «Embryologie chimique» (Fig. 2) by Jean Brachet (Brachet, 1945) which at that time became our Bible in the laboratory. It was a gift in 1949 by the young Swedish student Lars Ehrenberg whose enthusiasm to help post-war Bulgaria brought him as a volunteer in our youth work brigades.

Without any supply of special reagents and equipment I started work. Influenced by the book of Brachet, I isolated RNase from my own saliva (later from calf pancreas) and used it to carry out cytochemical studies on nucleic acids during mechanical injury of tissues. Thus, I obtained my first experimental results indicating the role of RNA degradation products in the wound process.

Despite the bad working conditions, an enthusiastic group of talented young people formed the nucleus of our future Institute of Molecular Biology. The lack of an ultracentrifuge led us to discover that electrophoretic separation of RNA in agar gels is a much better method for nucleic acid fractionation than ultracentrifugation (Tsanev, 1965). This was my first achievement and soon this technique and its many variations became a preferred procedure world- wide.

In 1969-71 you proposed an original mathematical model of cell prolifera- tion and differentiation. How does this model account for the networks of gene regulation controlling development and differentiation?

In 1961 I read the paper of Jacob and Monod who proposed a model explaining the regulation of gene expression in prokaryotes (Jacob and Monod, 1961). It was a fascinating idea and I was tempted to apply this model to eukaryotes, not realizing yet the important consequences of this idea.

At that time I used to spend our summer vacation with my family on the Black Sea coast in the International House of Scientists "Joliot Curie" near Varna. There I met on the beach the Bulgarian mathematician Blagovest Sendov (now member of our Academy and Bulgarian Ambassador to Japan in Tokyo). Burning on the sand under the hot August sun we discussed science and I started to explain a model of cellular activity based on interrelated genes and the equations that may express the control of their activity. Sendov was very much interested in this idea. In these early days of informatics he was involved in work with computers that were already installed in the Institute of Mathematics at the BAS. Finally we decided to use a computer to study a model of cellular activity based on a network of genes interrelated on the basis of equations describing the synthesis of mRNA, controlled by DNA-protein interactions and programming the ribosomes for the synthesis of proteins.

After the vacation we started computer simulations of our model using the Russian computer "Minsk 22" that occupied a whole room in the Institute of Mathematics and worked for days to solve some of our simulation experiments. With today's modern computers, such problems take only seconds to be solved.

We adapted to eukaryotic cells the concept of gene regulation based on a circuit of two sets of genes - one controlling cell differentiation and another mitotic activity - interrelated on the basis of mutual repression. The main process which affected our model was the reversible interaction of proteins with DNA. We introduced an equation describing the synthesis of some proteins (trans factors) that controlled the activity of genes by binding to their specific DNA sequences (cis elements). It was clear that such reversible trans/cis interactions should obey the Law of Mass Action, a law formulated in 1867 by Guldberg and Waage.
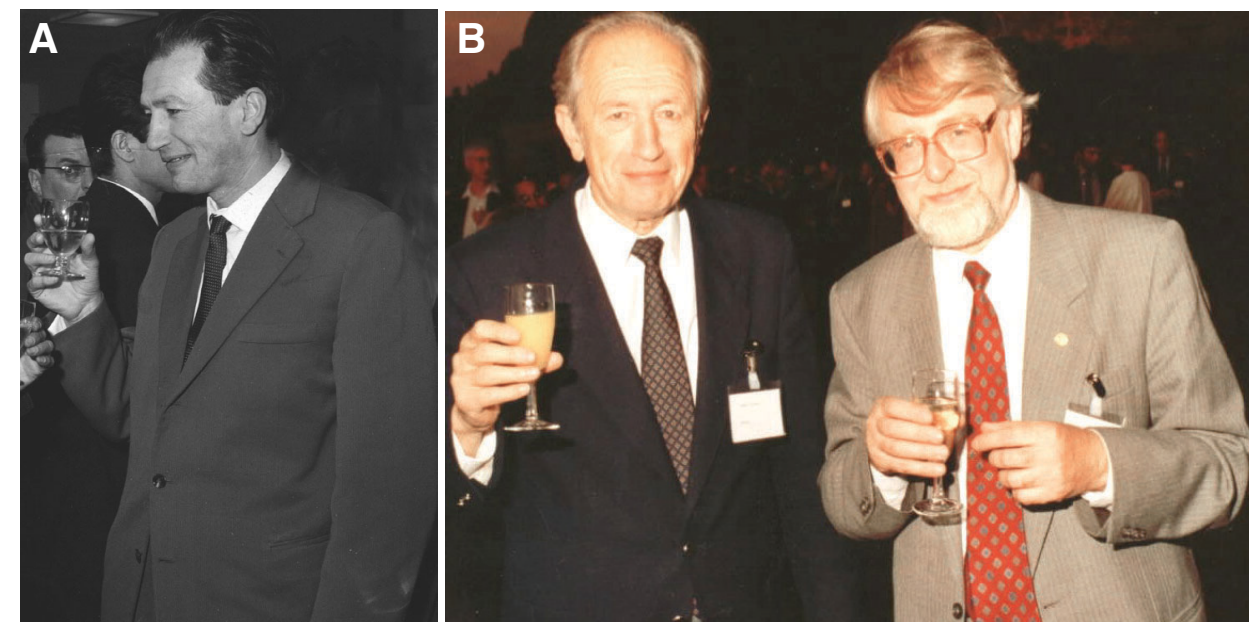

Fig. 3. Fellowships abroad in the 1960 s and 1970s. (A) At a reception at the International Atomic Agency, Sacley, France (1963). (B) With Vladimir Skulachev (right) in Moscow (1979). 
Today we know that some of these trans-acting proteins are repressors and others are activators of gene activity but our approach would still apply. Based on the law of mass action, the fraction of time $\theta$ a trans-cis complex is free of repressor or is bound to an activator can be expressed as: $\theta=1 / 1+(\sigma . T)^{\mathrm{n}}$ where $\mathrm{n}$ is 1 if $\mathrm{T}$ is a repressor or -1 if it is an activator and $\sigma$ is the equilibrium constant of a given trans-cis complex involving the trans factor $\mathrm{T}$. Thus, the synthesis of mRNA should be proportional to the fraction of time $\theta$ that the cis element is free of repressor $(n=1)$ or is associated with an activator $(n=-1)$.

The use of $\theta$ in the equation of mRNA synthesis imposes features of non-linearity to the whole system. The properties of such a system depend on its parameters. There is a definite space of parameters when small changes in their values cause small changes in the properties of the system. In a non-linear system when the parameters reach the boundaries of this space, small changes of their values lead to drastic, saltatory changes in the property of the system. These "jumps" were clearly revealed when we carried out computer experiments with models of different cellular systems: a proliferating cell culture, a regenerating mammalian liver (Sendov and Tsanev, 1968), liver cancer, wounded skin epidermis, as well as a model of a worm-like creature called by us "Kylindros" (Tsanev and Sendov, 1971b).

Fig. 4 shows the abrupt changes of liver "regeneration" after $2 / 3$ "hepatectomy" (simulated by decreasing the number of cells) upon changing one of the parameters of the system. It is seen that there are regions of stability where changes in the concentration of a critical repressor synthesized by differentiation genes do not affect the reaction of the system. However, extremely small deviations out of these regions of stability, change drastically the behaviour of the system and an unlimited growth is obtained.

With the model "Kylindros" we obtained sudden morphological changes when the half-life of the stored mRNA in the oocyte changed (Fig. 5). Thus, changes in the stability of mRNA in the oocyte will lead to phenotypic changes of a species.

The validity of our model was confirmed with computer experi-

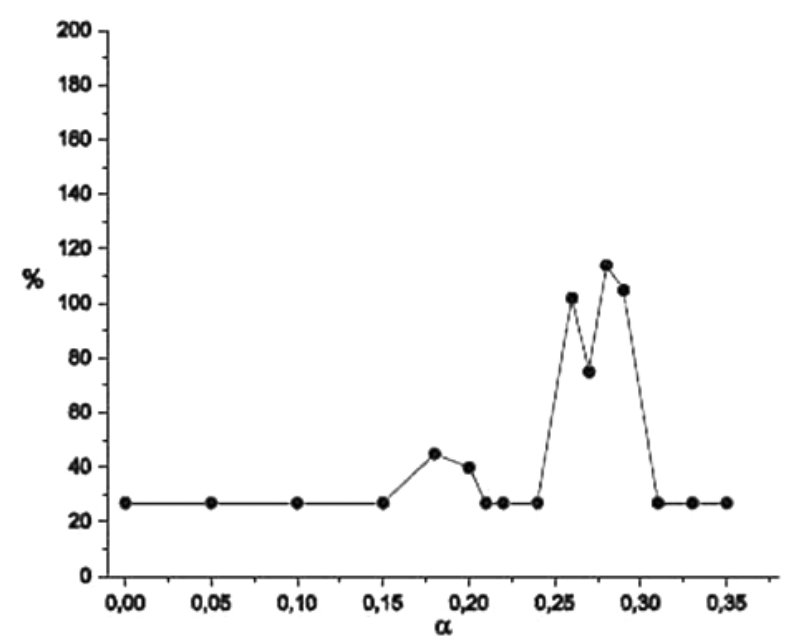

Fig. 4. A non-linear genome. Effect of the parameter $\alpha$ (which determines the distribution of a diffusible repressor between the cells and the intercellular space) on the extent of restoration of the lever model as simulated by the computer after 66\% "hepatectomy" (Sendov and Tsanev, 1968).
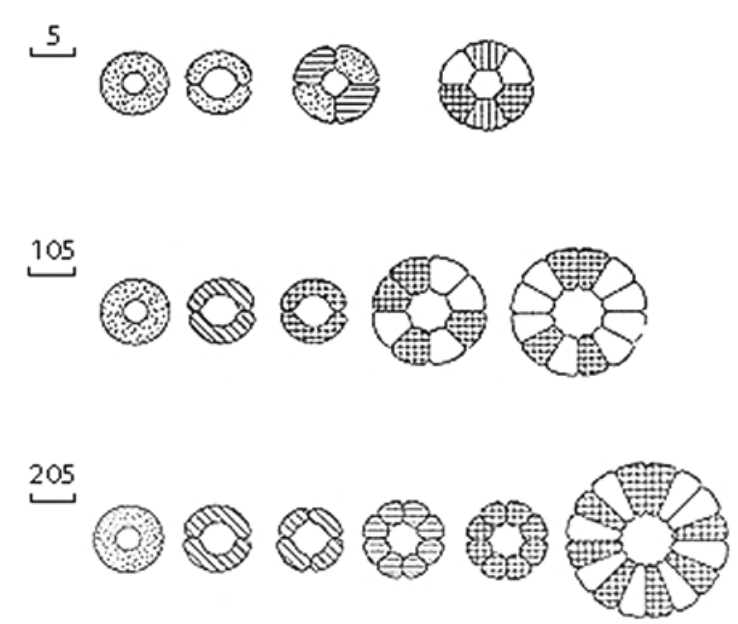

Fig. 5. The Kylindros model. Cross sections of the model Kylindros showing different phenotypes depending on the half-life time lexpressed as computer steps) of the mRNA stored in the egg (Tsanev and Sendov, 1971b).

ments on the model of epidermis. It simulated well the random distribution of mitotic cells, their diurnal variations and increased mitotic activity after injury, simulated by decreasing the number of cells in a segment of the model. It is interesting that in these experiments, our model predicted several fading mitotic waves after injury - 2, 3 or more, depending on various parameters as found in some real experiments where two maxima of mitotic rate were observed on days 1-2 and 7 (Rohrbach et al., 1977). Our real experiments have shown that injury leads to degradation of RNA and this was used to simulate injury in the model.

Some authors have argued that the presence of several mitotic waves following injury speaks against a model of functionally interconnected operons. As seen, our model experiments show that such a conclusion is not correct; the model did predict such results. May I say that in this case the computer mouse predicted very well some properties of the laboratory mouse!

In all cases the computer experiments with our models have shown that the behaviour of these systems is a non-linear function of their parameters. When the latter cross some space boundary, abrupt changes take place leading either to a chaotic unstable state, or to a new steady state, characterized by a different set of active genes. The idea that non-linear relationships should take place in the genome has been suggested by other authors. To explain saltatory phenomena in evolution, non-linear models have been proposed by introducing variables, as for example non-linear fields, genome operators, stochastic models (Karev et al., 2003), artificially constructed non-linear genetic networks etc. In fact all these approaches did not contribute to understanding the molecular mechanisms underlying the process of new pattern formation. Such formal approaches substitute one unknown factor for another. In our studies we reached such non-linear relations on the basis of a natural molecular process - interactions between specific DNA sequences (cis elements) and regulatory factors (trans proteins) as governed by the Law of Mass Action. This answers one of the objectives of science to explain more and more with less and less.

Being among the first to use the Law of Mass Action in a mathematical model of cell proliferation, it was gratifying to read a 


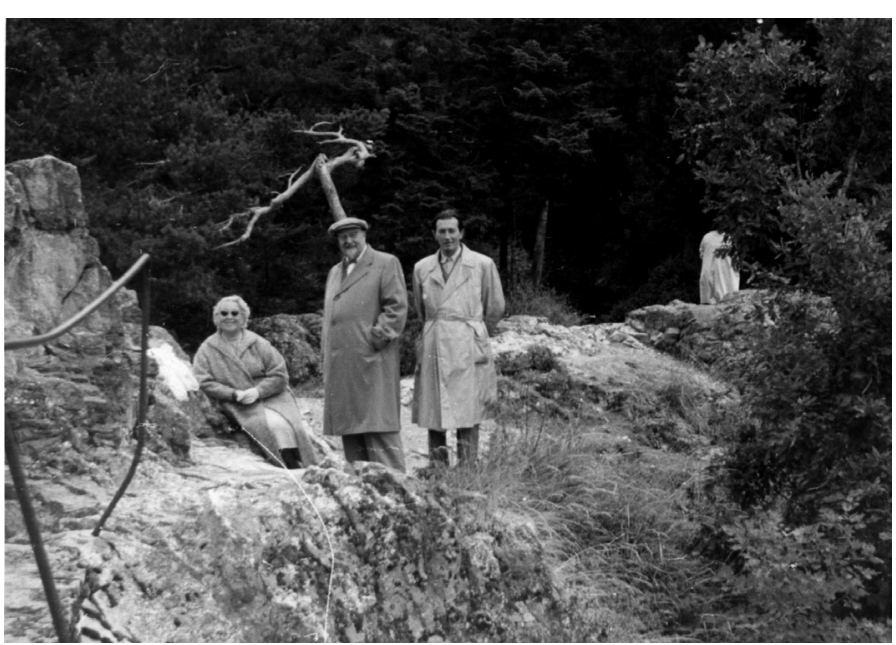

Fig. 6. Talking about Evolution. With Alexander Oparin and his wife Nina Petrovna in the Rila mountains (1962).

while ago what the former editor of "Nature" John Maddox wrote in 1992: So should molecular biologists mend their ways, resurrecting the Law of Mass Action (now conspicuous by its absence from what they publish) (Maddox, 1992).

Development and Evolution were two recurrent themes in the main projects of your laboratory. Early in the sixties you talked with Alexander Oparin (Fig. 6), who provided the first and principal modern appreciation of the origin of life. You were particularly interested in the evolution of histones and its implications for histone binding and role on DNA. In the light of the resurgent interest in Darwin's theory, what could be the impact of genetic network non-linearity on the evolution of organic forms?

I wonder if Darwin was right in adopting the motto "Natura non facit saltus"2? Some contradictory features of the evolution of species have caused many debates and disagreements concerning the pace of evolution. The Darwinian phyletic gradualism was opposed to the "un-Darwinian" abrupt changes ("quantum jumps"). Long geological periods of "frozen" evolution were found in contrast to the periods of rapid emergence of new biological forms (e.g. the Cambrian explosion). The mass extinction of species during some geological periods also remains still unexplained. There was no theory at the molecular level that could provide a natural model explaining these varying aspects of evolution. Attempts to explain these peculiar features have caused the division of opinions referred to as "gradualist-saltationists" schism.

As I already explained, gene regulation based on interactions between trans-acting proteins and cis-DNA sequences leads to non-linear differential equations describing gene activity. Thus, the genome becomes a non-linear system as a function of its parameters. The parameter space is divided into zones of stability (gradual changes of the phenotype) and zones of unstable "chaotic" behaviour - abrupt changes ("jumps") leading either to lethality for a living system (extinction of species) or to a new stable state representing the emergence of a new biological form for the natural selection. Our data have also shown the importance of

\footnotetext{
2 Nature does not make a leap (Webster's dictionary).
}

some parameters for the stability of a cellular system. Such are the equilibrium constants of the trans/cis interactions, the threshold values of the concentrations of trans proteins, membrane permeability, the half-life of different mRNAs etc. Of special interest is the organization of DNA in separate domains by some tightly bound proteins that seem to be evolutionary conserved (Avramova et al., 1989).

The conclusion that the genome is a non-linear system has important implications explaining in a natural way the different aspects of the biological evolution. A genetic drift caused by small Darwinian changes, even without any adaptive values, may be in fact the driving force of evolution by shifting the molecular parameters of a population outside the boundary of the stability zone. The results of such small changes may be species variations - within the zone of stability, extinction of species (within the zone of unstable behaviour), emergence of new species (transition into a new zone of stability) and long periods of stasis separating these events. This is a new approach to the problem of evolution which will be very helpful in reconciling different view points.

Life on Earth appeared more than 3,700 billion years ago, i.e. very soon after our planet was formed. Such a short period for life to emerge has led some authors (e.g. Francis Crick) to believe that life was created somewhere else in the Universe and then transferred to the Earth. The period of about 1,300 billion years for life to appear on Earth is really short if evolution proceeded according to Darwinian phyletic gradualism. However, the presence of nonlinear relations in the genome will strongly accelerate the pace of evolution. It cannot be excluded that in the prebiotic time, nonlinear relations were established among the new biopolymers, leading rapidly to new forms. Thus the famous motto of ancient philosophers "Natura non facit saltus" 2 is far from being true. Darwin was right to insist on the role of small variations, but he could not know what molecular biology was going to discover a century later.

Back in 1971, when nucleosomes had not yet been described, you proposed an epigenetic mechanism of differentiation and carcinogenesis based on the assumption that regulatory units could be based on "specific arrangement of histone and non-histone proteins". What were your first steps in the field of chromatin structure and function and how did you come so early in time to the idea of epigenetic information?

My first studies on the role of nucleic acids in wound healing induced my interest in the molecular mechanisms of cell proliferation and differentiation. This led me to study the molecular organization of chromatin, a problem that became a central objective of our team. On the basis of electron-microscopic observations I reported in 1975 details on the substructure of the nucleosome showing the possibility of its splitting into two half-nucleosomes (Tsanev, 1978). The behaviour of nucleosomes during DNA replication and transcription then became the focus of our further studies. I was especially interested in the problem whether stable DNA-protein complexes may be inherited playing the role of a new type of biological information - epigenetic information (Tsanev and Sendov, 1971a).

As far as the histone code is concerned, first of all I would like to clarify what I think we should understand by epigenetics, because there is some confusion in the literature concerning this notion. Epi- comes from the Greek, meaning "upon", "after", and 

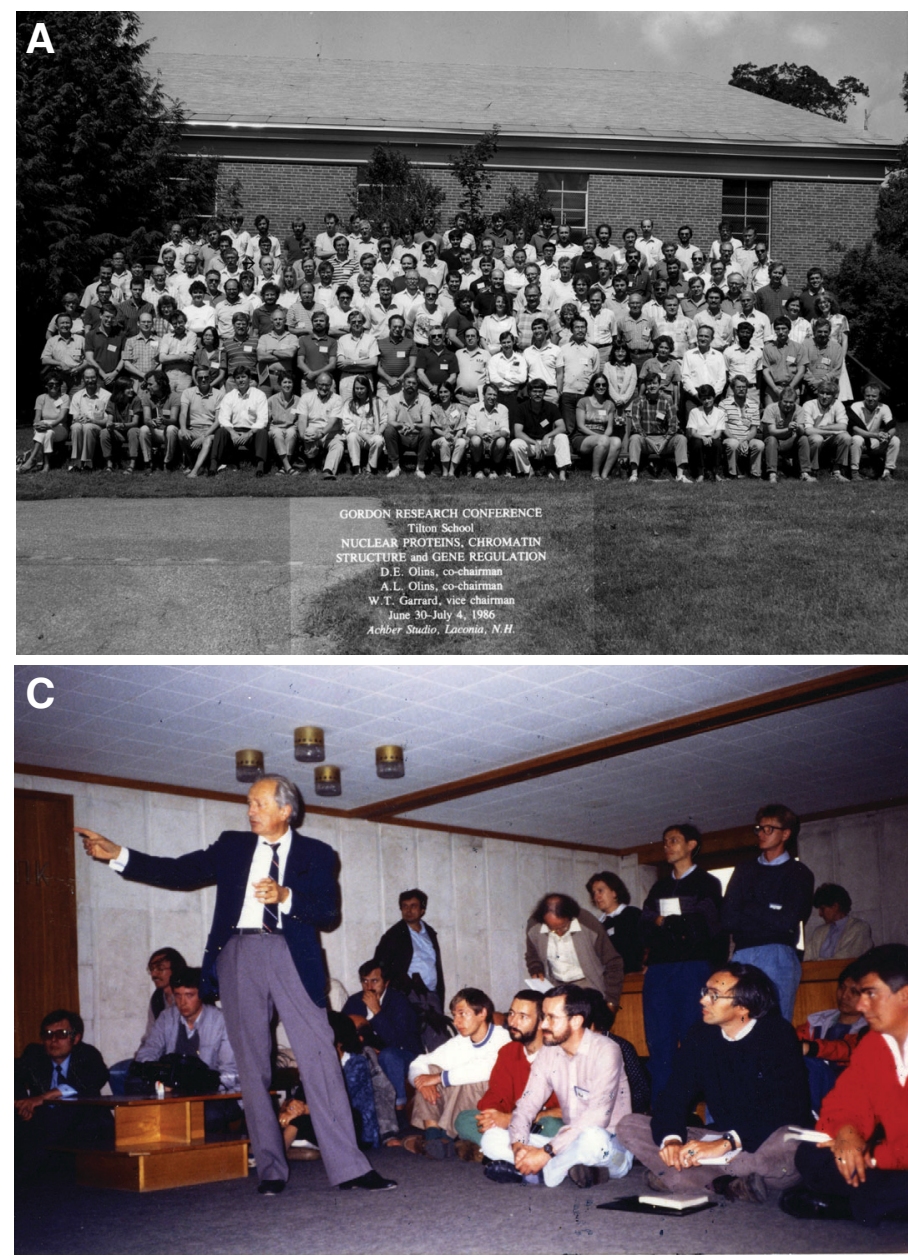

"following". Thus, epigenetic information is a stable factor with the following characteristics: It affects gene expression, it is independent of DNA sequences and it is transferred to the progeny (it is stably inherited).

Histones attracted our attention due to their peculiar properties: 1) They bind firmly to DNA without recognizing DNA sequences; 2) The genes that code for histones are repeated hundreds of times; 3) Histones are highly conserved in evolution, showing very few mutations. For example, while many proteins undergo tens to hundreds of mutations per one million years per 100 amino acids, the most conservative histone $\mathrm{H} 4$ has undergone only 1 mutation in such a period. This shows that even one mutated gene in the histone repeat will produce "false" histones which would not be tolerated, even though the bulk of normal genes in the repeated cluster will supply normal histones. This unusual and intriguing fact especially aroused my interest. One of the roles of histones is packaging and protecting DNA. However, when the problem is limited to such a role only, various other proteins can be used, as is the case of the proteins associated with sperm DNA. This suggested another important role of histones, which may be informational. Then, in 1969-1971 we put forward the idea that different arrangements of histones may play the role of an epigenetic histone code for the recognition sites of different genes, thus controlling gene expression. Concerning this model in 1971 we wrote in the Journal of Theoretical Biology: "Such a model does not require molecules able to recognize DNA base sequences but

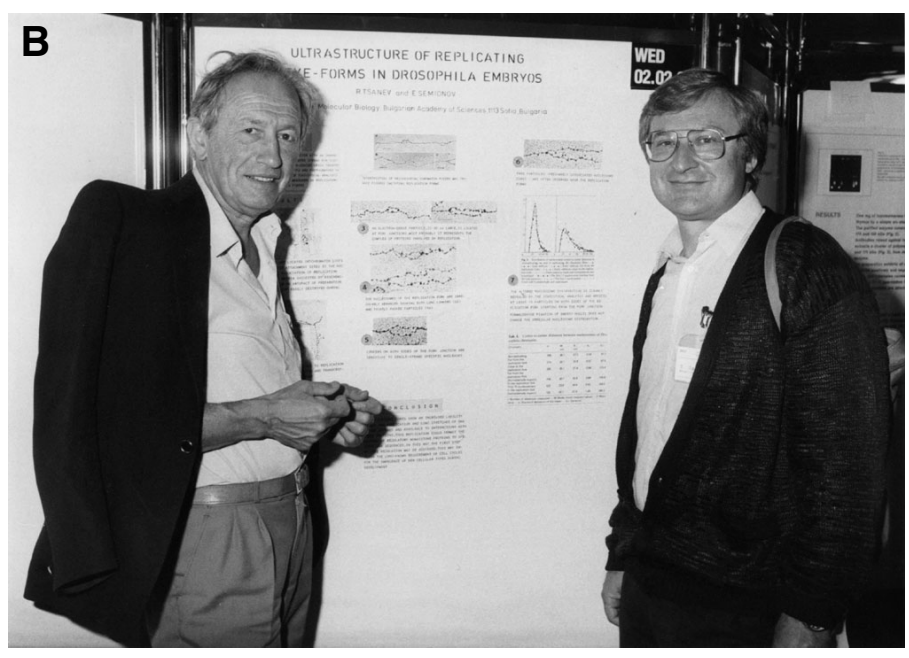

Fig. 7. Chromatin Meetings. (A) At the Gordon Conference (1986), Tsanev in row 5, 4th from the left to right (arrow). (B) FEBBS meeting 1988, with Tibor lgo-Kemenes (right). (C) "Witty and provocative in a debate....he imprinted a style of thinking on generations of young biologists". Talking to students and post-doc fellows, Nucleolar workshop, Suzdal, Russia (1989).

introduces a new information contained in the histone arrangements where the histone molecules play the role of elements of a new, epigenetic code" (Tsanev and Sendov, 1971b). Activation of genes "is realized by non-histone proteins which can specifically and irreversibly bind to different histone arrangements" at the initiation sites of genetic units. During the period of $1974-1978$ it was largely recognized that non-histone proteins are involved in the control of gene expression (Elgin and Weintraub, 1975), (Bekhor, 1978). In agreement with such a mechanism we found in different cellular systems metabolically stable non-histone proteins, a property needed to preserve the cellular type during DNA replication (Koleva and Tsanev, 1978; Srebreva et al., 1979).

At that time (1970-71) nucleosomes and their histone complement had not yet been discovered. When later it was found that DNA is organized in nucleosomes which have the same histone complement, our attention was focused on the non-allelic histone variants and their chemical post-translational modifications, which became well known in 1974-75. It could be calculated that with two variants of $\mathrm{H} 2 \mathrm{~A}$ and three of $\mathrm{H} 2 \mathrm{~B}, 18$ different nucleosomes can be assembled, without changing the overall design of the particle. If the two halves of the nucleosome contained different variants, then this number becomes 324. On the other hand it was also calculated that if all possible chemical modifications of only $\mathrm{H} 4$ took place, 240 different nucleosomes could arise (DeLange and Smith, 1975).

Nucleosome heterogeneity became the main object of our further research. We found differences between nucleosomes containing different histone variants. Thus, the accessibility to iodination of nucleosomes containing $\mathrm{H} 2 \mathrm{~A} 1$ or $\mathrm{H} 2 \mathrm{~A} 2$ variants was different and nucleosomes reconstituted with one or the other of these variants showed differences in the rate of DNAse I digestion (Venkov et al., 1985). Upon dissociation of nucleosomes with increasing salt concentration, a multiphase dissociation curve was obtained indicating the presence of different nucleosomes with respect to their stability (Vassilev et al., 1981). The transcriptionally active macronucleus of Tetrahymena was found to contain differ- 
ent histone variants from those of the inactive micronucleus (Allis et al., 1980). Similar differences we observed in the mouse centromeric chromatin (Russanova et al., 1989). A chromatin fraction containing rapidly labelled RNA also showed some differences in histone variants (Gabrielli et al., 1981).

Concerning the post-translational modifications of histones, we found that the most highly acetylated forms of $\mathrm{H} 3$ and $\mathrm{H} 4$ as well as the acetylated subspecies of $\mathrm{H} 2 \mathrm{~B}$ were localized almost entirely in the active chromatin fraction (Georgieva et al., 1982).

In 1979/80 we reached the following conclusion specifying our model: Histone variants could be involved in gene regulation by making the nucleosomes structurally and functionally heterogeneous. I also drew attention to the fact that on the basis of the structures of nucleosomes, the $\mathrm{H} 2 \mathrm{~A}-\mathrm{H} 2 \mathrm{~B}$ pair has an inner site for interaction with the $\mathrm{H} 3-\mathrm{H} 4$ tetramer and an external site for interaction with some nonhistone proteins and that evolutionary conservation of the protein-binding domains in $\mathrm{H} 2 \mathrm{~A}-\mathrm{H} 2 \mathrm{~B}$ shows the vital importance for the cell of some specific protein-protein interactions.

The idea that histones play a role in the control of gene expression met a serious difficulty in the accepted view that in the sperm nucleus of some species histones are lost completely and replaced by protamines. However, more detailed studies showed the presence of tightly bound proteins in mature sperm nuclei (O'Brien and Bellve, 1980a; O'Brien and Bellve, 1980b). Moreover, electron-microscopic studies of such nuclei revealed DNA fibres with nucleosome-like beads resistant to guanidine chloride, high salt and urea (Tsanev and Avramova, 1981). These data suggested that in the course of spermatogenesis somatic histones may have been preserved at some important sites of the genome. The complex protein structure of the sperm nucleus may be important for the reconstitution of a somatic nucleus preserving the sites with informational combinations of histones and their modifications. This specific structure may explain the need to replace the protamines with histones before the first replication takes place after fertilization (Nonchev and Tsanev, 1990).

We had previously shown that histones could be incorporated into chromatin in the absence of DNA replication, but the problem arises how a specific histone pattern could be transmitted to the progeny during DNA replication, what is the behavior of histones and nucleosomes during this process. The idea of a histone code supposed that during DNA replication old and new histones should not be distributed randomly between the two DNA strands. This
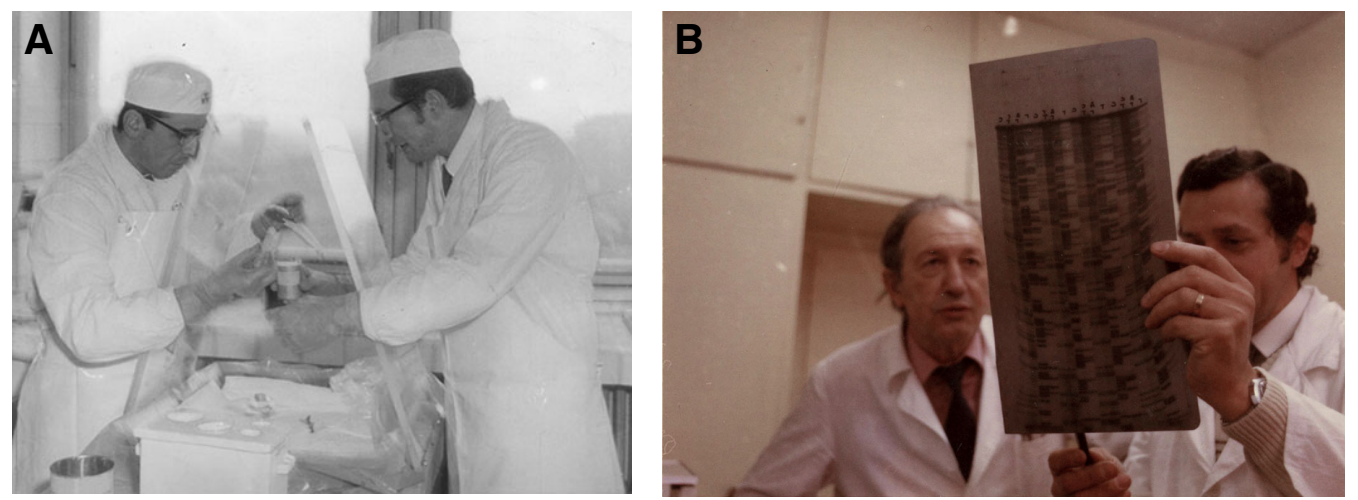

Fig. 8. A Man of the Bench. (A) In the hot room with Georgy Dessev (left). (B) What does the sequence say? (with Ivan Ivanov, right). question was first addressed experimentally by our group and we found that old histones remained associated with the old DNA strand and the new one - with the newly synthesized strand (Russev et al., 1980). We also found bilateral dispersive nucleosome segregation in groups of several adjacent nucleosomes distributed between the two daughter DNA molecules (Pospelov et al., 1982) The distribution of old and new histones between the two DNA strands could be explained by differences in the interaction of histones with the two complementary DNA strands. We were then able to demonstrate that the nucleosomal histone core, when in the chromatin, is slightly asymmetrically placed in the region where the $\mathrm{H} 2 \mathrm{~A}-\mathrm{H} 2 \mathrm{~B}$ pairs have been shown to interact with DNA (Chipev et al., 1987). Such an asymmetry was confirmed by later publications and by the fact that an alternating asymmetrical protection of DNA in nucleosomes was seen inside the chromatin higher-order structure (Staynov, 2000). An asymmetry in the relative position of these two dimers has also been detected by X-ray crystallography of core particles (Richmond et al., 1984). Thus, histones interact more strongly with one of the DNA strands and this may explain why the old histones remains attached to it during replication. I have suggested that a strong binding site may be due to arginine residues. The need for a subtle balance of binding forces may explain the extraordinary fact that mutations substituting lysine for arginine have not been tolerated in evolution. "This asymmetric interaction of histones with the two DNA strands may have important implications for the segregation mode of the old histone octamers during replication and for the cooperative alignment of the new nucleosomes" (Tsanev and Russev, 1974).

After our publications suggesting epigenetic information realized by histones and their interactions with non-histone proteins, there was a period of silence in the literature concerning epigenetics, which lasted about 20 years. Then, especially after 1990 there was an explosion of papers discussing epigenetic information. Although authors do not necessarily look back to see that the idea of an epigenetic information played by histones has been expressed 20-30 years earlier, the model of a code, based on non-allelic histone variants and histone tail modifications, read by regulatory proteins and governing downstream events, is now a central dogma of modern epigenetics (Strahl and Allis, 2000; Jenuwein and Allis, 2001). Still many aspects of the nature of the histone code remain elusive and I hope that among the different "omics" of today, epigenomics will soon find its place.

Based on the experimental results in your work, can you describe your view on the complexity of gene interactions during embryogenesis and morphogenesis and shortly summarize the essential points of your concept?

All data show that in the complex process of development at least three sources of information for gene expression and morphogenesis are used: genetic - available as DNA sequences, epigenetic-expressed as combinations of histone modifications ("histone 
code") and genetic networks - based on trans-cis interactions inducing non-linear dynamics in the genome.

Thus, not only in the evolution of species, but also during the individual development of a living organism, saltatory changes may take place that would explain some aspects of morphogenesis. Due to non-linear relations, changes in the parameters of a living system could drastically lead to cellular death, cellular transdetermination, to the appearance of a new forms and also to cancer. A good example is the transformation of the caterpillar into a butterfly - a saltatory transition from a creeping creature to a flying beauty. Nothing could be more different than these two forms. Another example is the unicellular organism Naegleria which in the absence of water is an amoeba and in water is transformed into a flagellate. For some time these two forms were considered to be two different species.

As a summary I would like to suggest tentatively the following four interrelated informational systems controlling the development of living organisms:

1. Genetic information expressed as DNA sequences coding for proteins and different RNAs.

2. Epigenetic information represented by histone variants and their chemical modifications involved in the control of gene expression.

3. Genetic networks - information for phenotypic expression, translation of the linear information in DNA into a three-dimensional phenotype - a new type of information realized by the genetic networks making the genome a non-linear system.

4. Audio-visual informational signals transmitted from parents to descents, forming by learning the behaviour of a species. I don't dare to discuss this aspect, but with the development of a neural system, this is likely to play a more and more important role.

It should be added that the parameters involved in all these informational steps play a crucial role both in the function of a living system and in the course of evolution. Speciation was not only due to genes per se, but to changing interrelations among genes - the structure of the genetic networks and their parameters. Let me finish with the probably striking conclusion that development, like the whole biodiversity on Earth, including our own human pres-

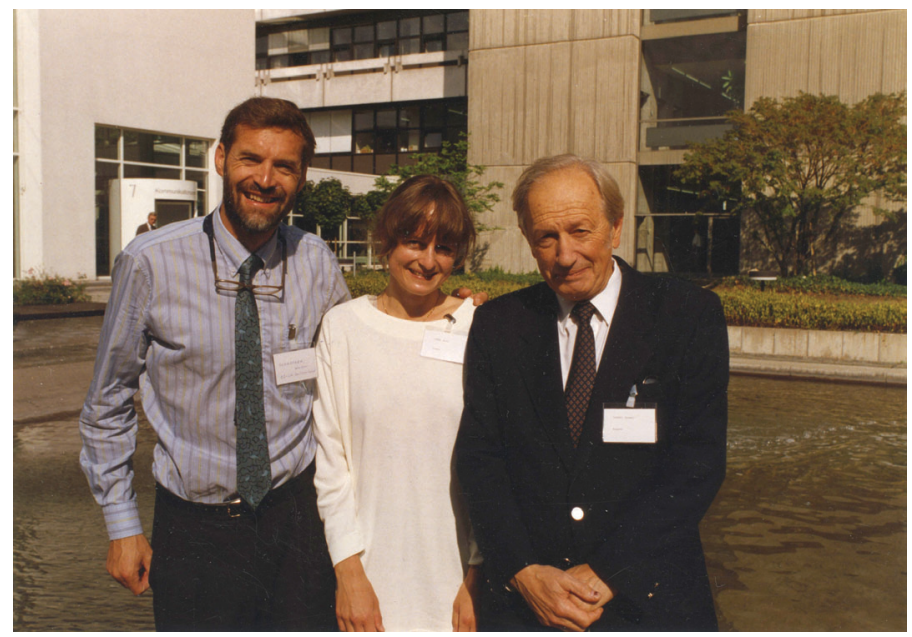

Fig. 9. Enhancers and Nucleosomes. R.G. Tsanev (right) with Walter Shaffner (left) and Weyma Lübbe (middle) at the DKFZ, September (1991) Heidelberg.

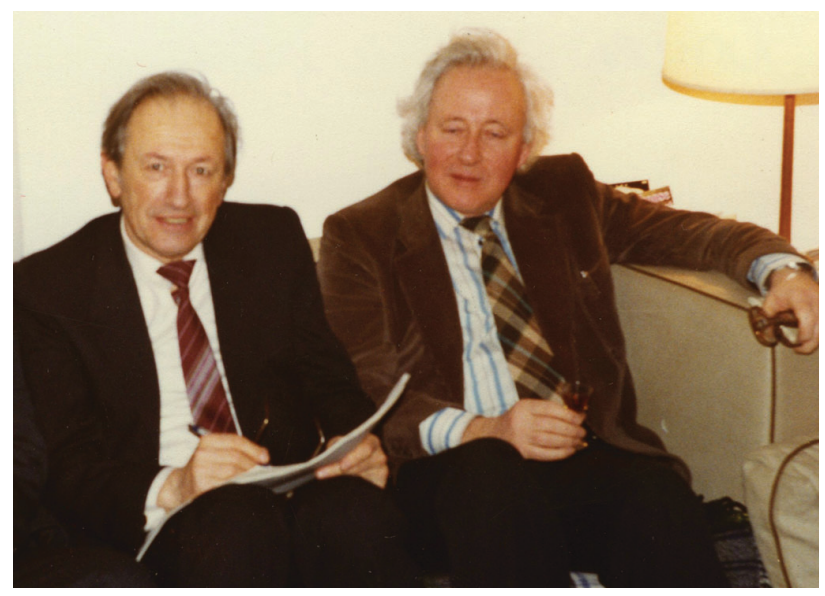

Fig. 10. Science and Politics. R.G. Tsanev (left) in London (1986), with the Russian geneticist and famous Soviet dissident Dr. Jores Medvedev (right).

ence, owes a great deal to the Law of Mass Action.

What type of new technologies will help to decipher the relationship between ontogenesis and evolution?

Studies on cloning and stem cells would be my first suggestion. Cloning may help to elucidate the factors that impose differences on organisms with identical DNA, which seems important for the role of ontogenesis in evolution. Such differences have been observed in cloned mammals as nicely illustrated by the "parents" of Dolly (Wilmut et al., 1997; Wilmut and Campbell, 1998). Cloning may also help to understand how a somatic cell nucleus is reprogrammed to start the development of a new organism. The development of a whole organism from a somatic cell - i.e. somatic embryogenesis - where the nucleus should be "cleaned" from some proteins to become able for reprogramming and stem cells may help to understand the mechanisms and factors controlling their differentiation into various cellular types, an important factor for ontogenesis.

How did creativity and original thinking help you in studying the role of chromatin in development and could you venture to say in what way imagination operates in art, literature and science?

I think that in addition to intellectual capacity, the study of such a complex structure as chromatin and such a multiphase process as development, requires a lot of creative imagination when observing how powerful life is in creating forms and functions. If I have made some contributions to Science it is due to the persistence and will to solve a problem and to overcome the difficulties always accompanying our activities and of course, the help of my enthusiastic and clever colleagues. The lack of appropriate working conditions was a stimulating factor to find new procedures. I enjoy the intellectual play to develop a hypothesis and to design experiments which could prove or disprove it. If I had some success in my work, it is connected with the constant and continuous occupation of my mind and imagination with possible solutions of a problem and sharing my efforts with my co-workers.

In all spiritual areas of human, creativity imagination plays an important role. This is evident in Art and Literature, which cannot 
be realized without imagination. In Science, imagination also plays a role that is not less important than intellect and knowledge. Having imagination to formulate an idea is an important step for the progress of Science. For me it is a real pleasure in seeing a theoretical idea experimentally proven, or even disproved, the latter being also a step forward. This demonstrates the power of human intellect and imagination. We have to recognize two types of scientists: the strict, pedantic researcher without imagination, who does not deviate from the bare facts (Wagner in Faust) and the creative scientist with an imagination looking ahead of the facts (Faust in Faust). Of course, both types of scientists are important and necessary for progress in Science; some are more like Wagner and others - like Faust!

\section{Acknowledgements}

We are grateful to Drs Christo Venkov, Stefan Dimitrov, Constantin Chipev, Georgy Markov and Dontcho Staynov for their help and encouragement.

\section{References}

ALLIS, C.D., GLOVER, C.V., BOWEN, J.K. and GOROVSKY, M.A. (1980). Histone variants specific to the transcriptionally active, amitotically dividing macronucleus of the unicellular eucaryote, Tetrahymena thermophila. Cell 20: 609-617.

AVRAMOVA, Z., MIKHAILOV, I. and TSANEV, R. (1989). An evolutionarily conserved protein fraction stably linked to DNA. Biochim Biophys Acta 1007: 109-111.

BEKHOR, I. (1978). Reconstitution of Chromatin. Academic Press, New York.

BRACHET, J. (1945). Embryologie chimique. Université Paris VI, Paris.

CHIPEV, C.C., IVANOVA, V.S. and TSANEV, R. (1987). Differential DNase I sensitivity of the two complementary nucleosomal DNA strands in cycloheximidetreated Ehrlich ascites tumor cells. J Biomol Struct Dyn 4: 1065-1077.

DELANGE, A. and SMITH, E. (1975). Histone Function and Evolution as wiewed by sequence studies. Associated Scient. Publ., Amsterdam.

ELGIN, S.C. and WEINTRAUB, H. (1975). Chromosomal proteins and chromatin structure. Annu Rev Biochem 44: 725-774.

GABRIELLI, F., HANCOCK, R. and FABER, A.J. (1981). Characterisation of a chromatin fraction bearing pulse-labelled RNA. 2. Quantification of histones and high-mobility-group proteins. Eur J Biochem 120: 363-369.

GEORGIEVA, E.I., PASHEV, I.G. and TSANEV, R.G. (1982). Distribution of acetylated forms of nucleosomal histones in fractionated chromatin. Arch Biochem Biophys 216: 88-92.

JACOB, F. and MONOD, J. (1961). Genetic regulatory mechanisms in the synthesis of proteins. J Mol Biol 3: 318-356.

JENUWEIN, T. and ALLIS, C.D. (2001). Translating the histone code. Science 293: 1074-1080.

KAREV, G.P., WOLF, Y.I. and KOONIN, E.V. (2003). Simple stochastic birth and death models of genome evolution: was there enough time for us to evolve? Bioinformatics 19: 1889-1900.

KOLEVA, S. and TSANEV, R. (1978). Metabolically stable non-histone chromosomal proteins in growing maize roots. Cell Differ 7: 83-88.
MADDOX, J. (1992). Is molecular biology yet a science? Nature 355: 201.

NONCHEV, S. and TSANEV, R. (1990). Protamine-histone replacement and DNA replication in the male mouse pronucleus. Mol Reprod Dev 25: 72-76.

O'BRIEN, D.A. and BELLVE, A.R. (1980a). Protein constituents of the mouse spermatozoon. I. An electrophoretic characterization. Dev Biol 75: 386-3404.

O'BRIEN, D.A. and BELLVE, A.R. (1980b). Protein constituents of the mouse spermatozoon. II. Temporal synthesis during spermatogenesis. Dev Biol 75: 405418.

POSPELOV, V., RUSSEV, G., VASSILEV, L. and TSANEV, R. (1982). Nucleosome segregation in chromatin replicated in the presence of cycloheximide. $\mathrm{J} \mathrm{Mol} \mathrm{Biol}$ 156: 79-91.

RICHMOND, T.J., FINCH, J.T., RUSHTON, B., RHODES, D. and KLUG, A. (1984). Structure of the nucleosome core particle at $7 \mathrm{~A}$ resolution. Nature 311: 532-537.

ROHRBACH, R., IVERSEN, O.H., RIEDE, U.N. and SANDRITTER, W. (1977) Effects of cellophane tape stripping of mouse skin on epidermal growth regulators (chalones). Beitr Pathol 160: 175-186

RUSSANOVA, V., STEPHANOVA, E., PASHEV, I. and TSANEV, R. (1989). Histone variants in mouse centromeric chromatin. Mol Cell Biochem 90: 1-7.

RUSSEV, G., VASSILEV, L. and TSANEV, R. (1980). Histone exchange in chromatin of hydroxyurea-blocked Ehrlich ascites tumour cells. Nature 285: 584-586.

SENDOV, B. and TSANEV, R. (1968). Computer simulation of the regenerative processes in the liver. $J$ Theor Biol 18: 90-104

SREBREVA, L., RUSSEV, G. and TSANEV, R. (1979). Metabolic stability of nonhistone chromosomal proteins in Ehrlich ascites tumour cells. Int J Biochem 10: 691 695.

STAYNOV, D.Z. (2000). DNase I digestion reveals alternating asymmetrical protection of the nucleosome by the higher order chromatin structure. Nucleic Acids Res 28: 3092-3099.

STRAHL, B.D. and ALLIS, C.D. (2000). The language of covalent histone modifications. Nature 403: 41-45.

TSANEV, R. (1965). Fractionation of RNA in agar-gel electrophoresis studied by direct ultraviolet spectrophotometry. Biokhimiia 30: 124-127.

TSANEV, R. (1978). The substructure of nucleosomes. Academic Press.

TSANEV, R. and AVRAMOVA, Z. (1981). Nonprotamine nucleoprotein ultrastructures in mature ram sperm nuclei. Eur J Cell Biol 24: 139-145.

TSANEV, R. and RUSSEV, G. (1974). Distribution of newly synthesized histones during DNA replication. Eur J Biochem 43: 257-263.

TSANEV, R. and SENDOV, B. (1971a). An epigenetic mechanism for carcinogenesis Z Krebsforsch Klin Onkol Cancer Res Clin Oncol 76: 299-319.

TSANEV, R. and SENDOV, B. (1971b). Possible molecular mechanism for cell differentiation in multicellular organisms. $J$ Theor Biol 30: 337-393.

VASSILEV, L., RUSSEV, G. and TSANEV, R. (1981). Heterogeneity of nucleosomes upon dissociation with salts. Int J Biochem 13: 1247-1255.

VENKOV, C., RUSSANOVA, V., IVANOVA, V. and TSANEV, R. (1985). Differences in the mode of iodination of $\mathrm{H} 2 \mathrm{a}$ variants in chromatin. Int J Biochem 17: 911-916.

WILMUT, I. and CAMPBELL, K.H. (1998). Quiescence in nuclear transfer. Science 281: 1611.

WILMUT, I., SCHNIEKE, A.E., MCWHIR, J., KIND, A.J. and CAMPBELL, K.H. (1997). Viable offspring derived from fetal and adult mammalian cells. Nature 385: 810813. 


\section{Further Related Reading, published previously in the Int. J. Dev. Biol.}

See our Special Issue Fertilization edited by Paul M. Wassarman and Victor D. Vacquier at: http://www.ijdb.ehu.es/web/contents.php?vol=52\&issue=5-6

Dynamic alterations of linker histone variants during development James S. Godde and Kiyoe Ura Int. J. Dev. Biol. (2009) doi: 10.1387/ijdb.082644jg

A histone $\mathrm{H} 1$ variant is required for erythrocyte maturation in medaka Osamu Matsuoka, Norihisa Shindo, Daisuke Arai and Toru Higashinakagawa Int. J. Dev. Biol. (2008) 52: 887-892

Dynamic distribution of the replacement histone variant $\mathrm{H} 3.3$ in the mouse oocyte and preimplantation embryos Maria-Elena Torres-Padilla, Andrew J. Bannister, Paul J. Hurd, Tony Kouzarides and Magdalena Zernicka-Goetz Int. J. Dev. Biol. (2006) 50: 455-461

Histone methylation defines epigenetic asymmetry in the mouse zygote.

Katharine L Arney, Siqin Bao, Andrew J Bannister, Tony Kouzarides and M Azim Surani Int. J. Dev. Biol. (2002) 46: 317-320

Multiple stage-dependent roles for histone deacetylases during amphibian embryogenesis: implications for the involvement of extracellular matrix remodeling.

S Damjanovski, L M Sachs and Y B Shi

Int. J. Dev. Biol. (2000) 44: 769-776

\section{OTHER INTERVIEWS}

Idealism and romantic patriotism for science - an interview with José Francisco David-Ferreira Maria Carmo-Fonseca and José Francisco David-Ferreira Int. J. Dev. Biol. (2009) 53 doi: 10.1387/ijdb.072314mc

Early mammalian embryo: my love. An interview with Andrzej K. Tarkowski Marek Maleszewski and Andrzej K. Tarkowski

Int. J. Dev. Biol. (2008) 52: 163-169

In pursuit of communication. An interview with Bob Ruben

Fernando Giraldez and Bernd Fritzsch

Int. J. Dev. Biol. (2007) 51: 439-445

From observations to paradigms; the importance of theories and models. An interview with Hans Meinhardt

Richard Gordon and Lev Beloussov

Int. J. Dev. Biol. (2006) 50: 103-111

Direct physical formation of anatomical structures by cell traction forces. An interview with Albert Harris

Lev Beloussov

Int. J. Dev. Biol. (2006) 50: 93-101

Putting evo-devo into focus. An interview with Scott F. Gilbert

Alexander T. Mikhailov

Int. J. Dev. Biol. (2005) 49: 9-16

A life in research on lens regeneration and transdifferentiation. An interview with Goro Eguchi

Kunio Yasuda

Int. J. Dev. Biol. (2004) 48: 695-700

The extracellular matrix in development and regeneration. An interview with Elizabeth D. Hay

Robert L. Trelstad

Int. J. Dev. Biol. (2004) 48: 687-694

2006 ISI **Impact Factor $=3.577^{* *}$

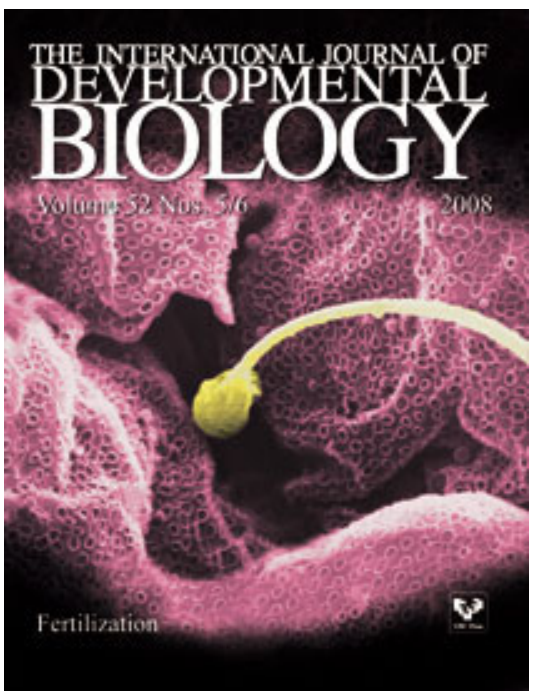

